\title{
Role of COX2 as a Biomarker for Estimating Survival of Patients With Clinical Stage I Gastric Cancer
}

\author{
HYUN JOO YOO ${ }^{1}$, TAE JUNG KIM ${ }^{2}$, DONG JIN KIM ${ }^{1}$ and WOOK KIM ${ }^{1}$ \\ ${ }^{1}$ Department of Surgery, College of Medicine, The Catholic University of Korea, Seoul, Republic of Korea; \\ ${ }^{2}$ Department of Pathology, College of Medicine, The Catholic University of Korea, Seoul, Republic of Korea
}

\begin{abstract}
Background/Aim: The prognostic significance of biomarkers related to gastric cancer prognosis has not been fully elucidated. The aim of study was to use immunohistochemical biomarkers to reveal prognosis. Patients and Methods: A total of 682 patients who had undergone curative surgery were evaluated regarding the correlation of prognosis and immunohistochemical biomarkers. Results: The COX2-positive groups showed a poor 5-year overall and disease-free survival. Further analysis revealed that COX2 positivity was a significant risk factor for poorer disease-free survival in the group with clinical stage I disease $(p=0.016)$. We also noted a marked trend between COX2 positivity and poorer overall survival. The COX2-positive group showed general postoperative pathological up-staging compared with the COX2-negative group. Conclusion: This study showed the potential of COX2 as a biomarker for gastric cancer prognosis. Preoperative evaluation of COX2 might be a useful tool for generating optimal treatment strategies in patients with clinical stage I gastric cancer.
\end{abstract}

Despite the therapeutic advancements that have been made in recent years, in 2015, gastric cancer was ranked the fifth most common cancer and was third in terms of cancerrelated deaths (1). After patients with gastric cancer have received appropriate local treatment (e.g. endoscopic submucosal dissection and extended gastrectomy), it is common for the cancer to relapse, thereby necessitating further treatment. In some cases, cancer diagnosis is misjudged and underestimated, resulting in insufficient treatment (2). To overcome this issue, various biomarkers

Correspondence to: Dong Jin Kim, MD, Ph.D., Assistant Professor, Division of Gastrointestinal Surgery, Department of Surgery, Eunpyeong St. Mary's Hospital, College of Medicine, The Catholic University of Korea, 1021, Tongil-ro, Eunpyeong-gu, Seoul, 03312, Republic of Korea. Tel: +82 220304646, Fax: +82 220304647, e-mail: djdjcap@catholic.ac.kr

Key Words: Stomach neoplasms, immunohistochemistry, cyclooxygenase 2 , prognosis. that may help to estimate prognosis regardless of pathological stage have been studied. Some gastric cancer biomarkers, mostly related to cell proliferation and apoptosis, have been identified $(3,4)$. Since classic clinicopathological features cannot fully predict individual outcomes, it has been argued that molecular biomarkers might potentially be better prognostic traits for gastric cancer.

Studies on the prognostic significance of different molecular markers have included tumor protein 53 (p53), which has been proven to have a significant association with cancer mortality rates $(3,5)$. Interestingly, Li et al. have shown that co-expression of two or more markers, including $\mathrm{Ki67}$, a nuclear protein which is involved in proliferation, has a significant detrimental effect on the survival of patients with gastric cancer (6). Furthermore, cyclo-oxygenase-2 (COX2) has been linked to tumorigenesis, and much of the literature suggests that increased COX2 activity is related to more advanced stages of cancer (7). However, whether COX2 can be used as an independent prognostic factor in gastric cancer is still controversial (8).

The use of biomarkers as a tool for preoperative prognosis prediction and its implications have not yet been fully studied. In current clinical circumstances, immunohistochemistry is the main method used to examine postoperative specimens. In this study, we reinvestigated the potential prognostic use of biomarkers in preoperative settings.

\section{Patients and Methods}

Patients. We recruited a total of 738 patients from one institute who underwent gastric cancer surgery between March 2009 to December 2016 all by the same surgeon. Exclusion criteria included all those with clinical stage IV disease according to the seventh edition of the American Joint Committee on Cancer/Union for International Cancer Control classification (9), patients who underwent non-curative resection, and those who had had neoadjuvant chemotherapy. The remaining 682 patients were included in this study, and their specimens were examined by immunohistochemistry. The number of patients with increased expression of p53, COX2, and Ki67 was 665, 661 , and 678, respectively. The baseline clinicopathological characteristics were compared between the groups positive and 
Table I. Clinicopathological characteristics for the whole cohort of patients and according the result of specific immunostaining.

\begin{tabular}{|c|c|c|c|c|c|}
\hline Variable & & $\begin{array}{c}\text { Total } \\
(\mathrm{n}=682)\end{array}$ & $\begin{array}{l}\text { p53-positive group } \\
(\mathrm{n}=629)\end{array}$ & $\begin{array}{c}\text { COX2-positive group } \\
(\mathrm{n}=623)\end{array}$ & $\begin{array}{l}\text { Ki67-positive grour } \\
\qquad(\mathrm{n}=625)\end{array}$ \\
\hline \multirow[t]{2}{*}{ Gender } & Male & $433(63.5 \%)$ & $398(63.3 \%)$ & $396(63.6 \%)$ & $394(63.0 \%)$ \\
\hline & Female & $249(36.5 \%)$ & $231(36.7 \%)$ & $227(36.4 \%)$ & $231(37.0 \%)$ \\
\hline Age, years & Mean \pm SD & $63.8 \pm 11.9$ & $60.3 \pm 10.2$ & $64.1 \pm 12.0$ & $64.0 \pm 12.0$ \\
\hline \multirow[t]{3}{*}{ Approach, n (\%) } & Open & 77 (11.3\%) & $73(11.6 \%)$ & $74(11.9 \%)$ & $75(12.0 \%)$ \\
\hline & Laparoscopy & $589(86.3 \%)$ & $540(85.8 \%)$ & $528(84.8 \%)$ & $535(85.6 \%)$ \\
\hline & Open conversion & $16(2.3 \%)$ & $16(2.5 \%)$ & $16(2.6 \%)$ & $15(2.4 \%)$ \\
\hline \multirow[t]{6}{*}{ Resection, n (\%) } & Total gastrectomy & $74(10.8 \%)$ & $70(11.1 \%)$ & $68(10.9 \%)$ & $70(11.2 \%)$ \\
\hline & Completion total & $8(1.2 \%)$ & $7(1.1 \%)$ & $7(1.1 \%)$ & $7(1.1 \%)$ \\
\hline & Distal gastrectomy & $551(80.6 \%)$ & $512(81.4 \%)$ & $508(81.5 \%)$ & $508(81.3 \%)$ \\
\hline & Proximal gastrectomy & $42(6.1 \%)$ & $34(5.4 \%)$ & $34(5.5 \%)$ & $34(5.4 \%)$ \\
\hline & PPG & $6(0.9 \%)$ & $5(0.8 \%)$ & $5(0.8 \%)$ & $5(0.8 \%)$ \\
\hline & Whipple & $1(0.1 \%)$ & $1(0.2 \%)$ & $1(0.2 \%)$ & $1(0.2 \%)$ \\
\hline \multirow[t]{3}{*}{ cStage, n $(\%)^{*}$} & I & $474(69.5 \%)$ & $429(68.2 \%)$ & $424(68.1 \%)$ & $426(68.2 \%)$ \\
\hline & II & $107(15.6 \%)$ & $102(16.2 \%)$ & $102(16.4 \%)$ & $102(16.3 \%)$ \\
\hline & III & $101(14.8 \%)$ & $98(15.6 \%)$ & $97(15.6 \%)$ & $97(15.5 \%)$ \\
\hline \multirow[t]{8}{*}{ pStage, n (\%)* } & Ia & $405(59.4 \%)$ & $363(57.7 \%)$ & $359(57.6 \%)$ & $358(57.3 \%)$ \\
\hline & $\mathrm{Ib}$ & $67(9.8 \%)$ & $64(10.2 \%)$ & $66(10.6 \%)$ & $65(10.4 \%)$ \\
\hline & IIa & $50(7.3 \%)$ & $48(7.6 \%)$ & $46(7.4 \%)$ & $49(7.8 \%)$ \\
\hline & IIb & $50(7.3 \%)$ & $49(7.8 \%)$ & $49(7.9 \%)$ & $48(7.7 \%)$ \\
\hline & IIIa & $40(5.8 \%)$ & $37(5.9 \%)$ & $36(5.8 \%)$ & $37(5.9 \%)$ \\
\hline & IIIb & $40(5.8 \%)$ & $39(6.2 \%)$ & $39(6.3 \%)$ & $38(6.1 \%)$ \\
\hline & IIIc & $29(4.2 \%)$ & $28(4.5 \%)$ & $28(4.5 \%)$ & $29(4.6 \%)$ \\
\hline & IV & $1(0.1 \%)$ & $0(0 \%)$ & $0(0 \%)$ & $0(0 \%)$ \\
\hline
\end{tabular}

COX2: Cyclo-oxygenase 2; cStage: clinical stage; pStage: pathological stage; PPG: pylorus-preserving gastrectomy. *Seventh edition (9).

negative for each biomarker, and analysis of overall (OS) and disease-free (DFS) survival was performed. Biomarkers that led to significant differences in survival rates underwent further analysis depending on the preoperative clinical stage. Comparative analysis for clinicopathological characteristics was also carried out among the same clinical staging groups. This study was approved by the institutional review board (IRB number: SC18RESI0030).

Immunohistochemical scoring. Immunostaining for $\mathrm{p} 53, \mathrm{COX} 2$, and Ki67 proteins was performed on formalin-fixed paraffin-embedded tissue, using Ventana automated immunostainer BenchMark Ultra (Ventana Medical Systems, Tucson, AZ, USA) and an UltraView ${ }^{\mathrm{TM}}$ Universal DAB Detection Kit (Ventana Medical Systems) according to the manufacturer's instruction. Briefly, slides were dried at $60^{\circ} \mathrm{C}$ for $1 \mathrm{~h}$ and deparaffinized using EZ Prep (Ventana Medical Systems) at $75^{\circ} \mathrm{C}$ for $8 \mathrm{~min}$. Cell conditioning was performed using $\mathrm{CC} 1$ solution (Ventana Medical Systems) at $100^{\circ} \mathrm{C}$ for $48 \mathrm{~min}$. The representative paraffin sections with a thickness of $4 \mathrm{~mm}$ was immunostained with primary antibodies against COX2 (prediluted, rabbit monoclonal; Cell Marque, Darmstadt, Germany), Ki67 (prediluted, rabbit monoclonal; Ventana Medical Systems), and p53 (prediluted, rabbit monoclonal; Ventana Medical Systems). Palatine tonsils and normal liver tissue for p53 and Ki67, and colonic adenocarcinoma tissue for COX2 served as positive controls. Immunohistochemical staining was interpreted as positive when nuclear staining for p53 or Ki67 and cytoplasmic staining for COX2 were evident. The degree of immunoreactivity for each protein was evaluated at the invasive front of the tumor and was scored semiquantitatively on the basis of the proportion of positive cells. For p53 and COX2, positive samples were defined as those having over $10 \%$ positively stained cells.

Statistical analyses. Comparisons between groups were evaluated with Student's $t$-test in continuous variables and chi-squared and Fisher's exact test in nominal variables. Multivariate analysis to determine independent risk factors for postoperative complications underwent binary logistic regression analysis. Statistical significance was inferred when $p<0.05$. The Kaplan-Meier method was used to analyze the overall and disease-free survival. Survival analysis was performed globally and at each clinical stage for each immunohistochemical group. All of the analysis was performed using the software package, PASW 18.0 for Windows (SPSS, Inc., Chicago, IL, USA).

\section{Results}

A total 682 patients was included in this study, and tumor stage was distributed like followings according to 7 th AJCC/UICC: 405 (59.4\%) IA, 67 (9.8\%) IB, 50 (7.3\%) IIA, $50(7.3 \%)$ IIB, 40 (5.8\%) IIIA, 40 (5.8\%) IIIB, 29 (4.2\%) IIIC, and $1(0.1 \%)$ stage IV. We found that $10 \%$ of patients underwent total gastrectomy, whereas $80 \%$ underwent distal gastrectomy (Table I). As a whole, the numbers of patients with increased expression of p53, COX2, and Ki67 were 665, 661, and 678, respectively. Ki67 grading was considered positive according to cut-off values of $30 \%, 40 \%$, and $50 \%$. 

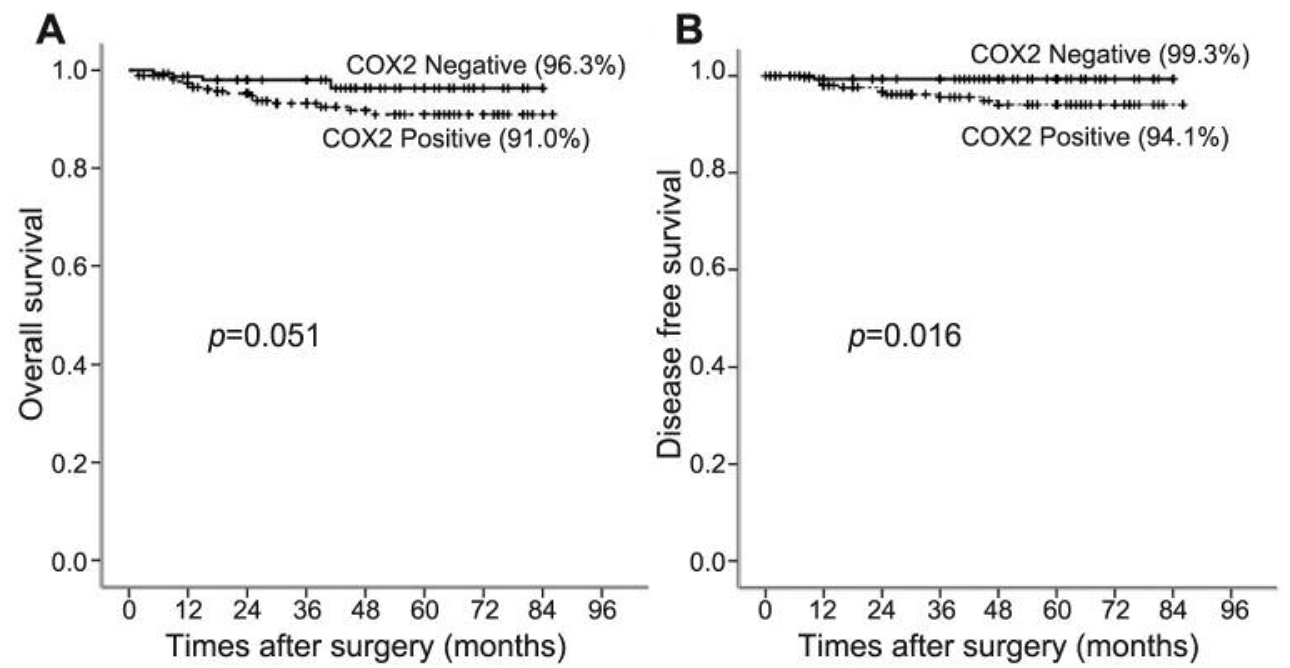

Figure 1. Survival of patients with clinical stage I gastric cancer according to cyclo-oxygenase 2 (COX2) status. The 5-year rates are shown in parentheses.

Table II. Five-year overall (OS) and disease-free (DFS) survival for each immunohistochemical group.

\begin{tabular}{|c|c|c|c|c|c|c|c|c|}
\hline \multirow[t]{2}{*}{ Variable } & \multicolumn{3}{|c|}{ Positive group } & \multicolumn{3}{|c|}{ Negative group } & \multicolumn{2}{|c|}{$p$-Value } \\
\hline & $\mathrm{N}$ & OS $(\%)$ & DFS (\%) & $\mathrm{N}$ & OS $(\%)$ & DFS (\%) & OS & DFS \\
\hline p53 & 293 & 82.0 & 86.8 & 335 & 86.5 & 89.7 & 0.142 & 0.283 \\
\hline $\mathrm{COX} 2$ & 405 & 82.4 & 86.6 & 217 & 89.2 & 91.8 & 0.018 & 0.040 \\
\hline Ki67_30\% & 520 & 82.3 & 87.0 & 155 & 89.9 & 90.4 & 0.040 & 0.276 \\
\hline Ki67 40\% & 467 & 82.5 & 86.8 & 208 & 87.9 & 89.9 & 0.072 & 0.333 \\
\hline Ki67_50\% & 408 & 82.8 & 87.0 & 267 & 87.6 & 89.6 & 0.110 & 0.440 \\
\hline
\end{tabular}

COX2: Cyclo-oxygenase 2; Ki67_\#\%: percentage cutoff for Ki67 positivity.

Survival analysis showed that 5-year OS for the COX2- and Ki67-30\%-positive groups was poor compared to the negative groups (positive vs. negative: COX2: $82.4 \%$ vs. $89.2 \%$, $p=0.018$; Ki67: $89.9 \%$ vs. $82.3 \%, p=0.040$ ). We also found that the COX2-positive group had worse 5-year DFS (positive $v s$. negative $=86.6 \%$ vs. $91.8 \%, p=0.040$ ) (Table II). For the rest of the groups, we did not find any significant differences in OS and DFS between the positive and negative groups.

Results from the survival analysis according to clinical stage showed that the main differences were observed in patients with clinical stage I. Results from the COX2 subgroup analysis indicated COX2 positivity to be a significant risk factor for poorer DFS (5-year survival COX2 positive $v s$. negative $=94.1 \%$ vs. $99.3 \%, p=0.016$ ). OS was also significantly reduced in patients with clinical stage I COX2-positive disease (Figure 1) (Table III).

Comparative analysis between patients with clinical stage I COX2-positive and -negative disease also demonstrated significant differences in pathological staging. Tumor size was larger in the COX2-positive group (2.8 $\pm 1.9 v s .2 .4 \pm 1.5 \mathrm{~cm})$. In terms of pathological depth, more $\mathrm{T} 3$ and $\mathrm{T} 4 \mathrm{a}$ cases were observed in the COX2-positive group compared to the COX2negative group [20 (7.4\%) vs. $3(1.9 \%)$, respectively, $p=0.015]$. For TNM staging, the COX2-positive group included more patients with stage III disease compared to the negative group [8 (3.0\%) vs. 0 (0\%), respectively, $p=0.029$ ] (Table IV). Moreover, the COX2-positive group tended to show pathological up-staging postoperatively. In short, there would be a possibility of stage migration compare to preoperative clinical stage. For the COX2-positive group, postoperative stage migrated even to stage IIIb, whereas the highest pathological stage migration was IIb in negative group.

\section{Discussion}

Despite ongoing efforts to identify factors which can be used to predict prognosis in patients with gastric cancer, the survival rates for these patients has not improved. 
Table III. Five-year overall (OS) and disease-free (DFS) survival for cyclo-oxygenase 2 (COX2)-positive and-negative groups according to clinical stage.

\begin{tabular}{|c|c|c|c|c|c|c|}
\hline \multirow{2}{*}{$\begin{array}{l}\text { Clinical } \\
\text { stage }\end{array}$} & & \multicolumn{2}{|c|}{ COX2-Positive } & \multicolumn{2}{|c|}{ COX2-Negative } & \multirow[t]{2}{*}{$p$-Value } \\
\hline & & $\mathrm{N}$ & Survival (\%) & $\mathrm{N}$ & Survival (\%) & \\
\hline \multirow[t]{2}{*}{ I } & OS & 268 & 91.0 & 156 & 96.3 & 0.051 \\
\hline & DFS & 268 & 94.1 & 156 & 99.3 & 0.016 \\
\hline \multirow[t]{2}{*}{ II } & OS & 69 & 78.9 & 33 & 72.9 & 0.930 \\
\hline & DFS & 69 & 84.4 & 33 & 78.1 & 0.513 \\
\hline \multirow[t]{2}{*}{ III } & OS & 68 & 49.2 & 28 & 65.1 & 0.145 \\
\hline & DFS & 68 & 56.1 & 28 & 61.1 & 0.208 \\
\hline
\end{tabular}

Clinicopathological factors that are related to prognosis include depth of tumor invasion, histological type, and clinical stage $(2,6)$. Owing to the fact that a major part of the cellular signaling pathways of cancer pathogenesis has not yet been thoroughly identified, molecular biomarkers that can affect individual outcomes are of great interest.

Traditionally, various cell-cycle-related molecular biomarkers were believed to be promising prognostic factors for gastric cancer survival. However, more recent research has shown that molecular biomarkers that are related to the growth or apoptosis of cancer cells may be useful for predicting the prognosis of patients with cancer (10). These biomarkers include p53, Ki67, human epidermal growth factor 2 (erb-b2 receptor tyrosine kinase 2, HER2/ERBB2), epidermal growth factor (EGFR), and $\operatorname{COX} 2(3,6)$. Additional studies have also implicated cell-cycle regulators including cyclin E, p53 and p27 as potential biomarkers. Recently, there has also been increased interest in the role of cell-adhesion molecules (e.g. E-cadherin, CD44, matrix metallopeptidase1) in cancer (11-13).

Loss of function mutations in $p 53$ have been shown to correlate with poor survival in cancer $(3,5)$. HER2, is known to up-regulate downstream proliferation signaling pathways and was once believed to be an important independent prognostic indicator. However, a systematic review in 2013 concluded that HER2 could be used to estimate the prognosis of patients with gastric cancer (14). Co-expression of Ki67, a biomarker for cell proliferation, with octamer-binding transcription factor 4 and proliferating cell nuclear antigen has been shown to negatively affect survival (6).

COX2 has been shown to be implicated in tumorigenesis in animal models (15). COX2 is also involved in the upregulation of angiogenesis due to increased vascular endothelial growth factors and prostaglandin $\mathrm{E}_{2}(16,17)$. There is also evidence suggesting that increased COX2 activity is related to more advanced tumor stage (7) but the prognostic role of COX2 in gastric cancer is still controversial. A meta-analysis study from 2014 concluded that elevated COX2 expression can be an independent risk factor for poor OS of patients with gastric cancer but no significant relationship was identified between COX2 overexpression and DFS (8).

The COX2 signaling pathway is responsible for the production of prostaglandins and other cytokines. As a result, significant efforts have been made to discover the association between COX2 and different hallmarks of cancer. In our study, the COX2 and Ki67-30\% positive groups showed significant differences in the 5-year OS, and the COX2-positive group also showed advanced pathological staging. We found that $66 \%$ of patients with clinical stage I gastric cancer and $34 \%$ of those with advanced gastric cancer (higher than stage I) were in the COX2-positive group. Moreover, patients with clinical stage I who were in the COX2-negative group showed better DFS. These results clearly illustrate the prognostic significance of COX2 in clinical stage I gastric cancer. Our findings are backed up by strong data that suggest that there is an association between cancer progression, aggressiveness, lymph nodal metastasis, and COX2 expression (18).

Traditionally, specific clinicopathological features are known to influence the survival of patients with gastric cancer. These include $\mathrm{T}$ and $\mathrm{N}$ staging, histological type, resection type, and the extent of lymphadenectomy $(2,19)$. Occasionally cases of very advanced gastric cancer, which were considered to be early-stage cancer in the preoperative setting, are diagnosed during surgery (2). Consequently, preoperative underdiagnosis can negatively alter the prognosis and the postoperative treatment plan of patients.

In current clinical practices, postoperative pathology has proven to be the most reliable method of predicting prognosis in gastric cancer. However, pathological diagnosis is based on full specimen analysis, which only can be achieved following surgery. Under these circumstances, the importance of a comprehensive diagnostic approach and a prediction of preoperative evaluation cannot be emphasized enough.

Despite not being statistically significant, the COX2positive group tended to show increased pathological upstaging compared to the preoperative clinical staging in our study. Further investigation into COX 2 positivity and its relationship with the clinical underdiagnosis of patients who showed unexpected outcomes after curative surgery would be informative.

As mentioned above, the current study represents an opportunity for the use of preoperatively evaluated molecular biomarkers as a tool to make more informed surgical decisions. In clinically obscure cases in which advanced stage is suspected, additional examination of biomarkers might change treatment plans, including the approach or extensiveness of the surgery.

Our study reveals the necessity for additional gene-based prognostic biomarkers. Since current trends in cancer biology have moved towards personalized medicine, a tailored operative approach based on standardized curative surgery is an important emerging topic. Molecular biomarkers which are 
Table IV. Pathological data of patients with clinical stage I gastric cancer according to cyclo-oxygenase 2 (COX2) status.

\begin{tabular}{|c|c|c|c|c|}
\hline \multirow[b]{2}{*}{ Variable } & & \multicolumn{2}{|c|}{$\mathrm{COX} 2$} & \multirow[b]{2}{*}{$p$-Value } \\
\hline & & Negative & Positive & \\
\hline \multirow[t]{2}{*}{ Gender, n (\%) } & Male & $99(63.5 \%)$ & $163(60.8 \%)$ & 0.606 \\
\hline & Female & $57(36.5 \%)$ & $105(39.2 \%)$ & \\
\hline Age, years & Mean \pm SD & $61.9 \pm 12.1$ & $63.8 \pm 12.3$ & 0.121 \\
\hline BMI, $\mathrm{kg} / \mathrm{m}^{2}$ & Mean \pm SD & $23.9 \pm 4.0$ & $23.7 \pm 3.4$ & 0.492 \\
\hline \multirow[t]{3}{*}{ Approach, n (\%) } & Open & $10(6.4 \%)$ & $16(6.0 \%)$ & 0.550 \\
\hline & Laparoscopy & $146(93.6 \%)$ & $250(93.3 \%)$ & \\
\hline & Open conversion & $0(0.0 \%)$ & $2(0.7 \%)$ & \\
\hline \multirow[t]{5}{*}{ Resection, n (\%) } & Total gastrectomy & $6(3.8 \%)$ & $15(5.6 \%)$ & 0.383 \\
\hline & Distal gastrectomy & $135(86.5 \%)$ & $236(88.1 \%)$ & \\
\hline & Proximal gastrectomy & $12(7.7 \%)$ & $12(4.5 \%)$ & \\
\hline & PPG & $1(0.6 \%)$ & $4(1.5 \%)$ & \\
\hline & Completion total & $2(1.3 \%)$ & $1(0.4 \%)$ & \\
\hline \multirow[t]{2}{*}{ LN dissection, n (\%) } & D1+ & $114(73.0 \%)$ & $198(73.9 \%)$ & 0.856 \\
\hline & D2 & $42(26.9 \%)$ & $70(26.1 \%)$ & \\
\hline Tumor size, $\mathrm{cm}$ & Mean \pm SD & $2.4 \pm 1.5$ & $2.8 \pm 1.9$ & 0.031 \\
\hline Retrieved LNs & Mean \pm SD & $34.5 \pm 14.2$ & $33.5 \pm 14.1$ & 0.482 \\
\hline \multirow[t]{5}{*}{ T-Stage, n (\%) } & Tis & $1(0.6 \%)$ & $0(0.0 \%)$ & 0.077 \\
\hline & $\mathrm{T} 1$ & $137(87.8 \%)$ & $225(84.0 \%)$ & \\
\hline & $\mathrm{T} 2$ & $15(9.6 \%)$ & $23(8.6 \%)$ & \\
\hline & $\mathrm{T} 3$ & $3(1.9 \%)$ & $17(6.3 \%)$ & \\
\hline & $\mathrm{T} 4 \mathrm{a}$ & $0(0.0 \%)$ & $3(1.1 \%)$ & \\
\hline \multirow[t]{5}{*}{ N-Stage, n (\%) } & No & $142(91.0 \%)$ & $232(86.6 \%)$ & 0.526 \\
\hline & $\mathrm{N} 1$ & $7(4.5 \%)$ & $20(7.5 \%)$ & \\
\hline & $\mathrm{N} 2$ & $6(3.8 \%)$ & $9(3.4 \%)$ & \\
\hline & $\mathrm{N} 3 \mathrm{a}$ & $1(0.6 \%)$ & $5(1.9 \%)$ & \\
\hline & $\mathrm{N} 3 \mathrm{~b}$ & $0(0.0 \%)$ & $2(0.7 \%)$ & \\
\hline \multirow[t]{6}{*}{ Stage, $\mathrm{n}(\%)^{*}$} & Ia & $131(84.0 \%)$ & $204(76.1 \%)$ & 0.293 \\
\hline & $\mathrm{Ib}$ & $13(8.3 \%)$ & $30(11.2 \%)$ & \\
\hline & IIa & $7(4.5 \%)$ & $17(6.3 \%)$ & \\
\hline & IIb & $5(3.2 \%)$ & $9(3.4 \%)$ & \\
\hline & IIIa & $0(0.0 \%)$ & $5(1.9 \%)$ & \\
\hline & IIIb & $0(0.0 \%)$ & $3(1.1 \%)$ & \\
\hline \multirow[t]{2}{*}{ Depth, n (\%) } & EGC & $138(88.5 \%)$ & $225(84.0 \%)$ & 0.202 \\
\hline & AGC & $18(11.5 \%)$ & $43(16.0 \%)$ & \\
\hline \multirow[t]{2}{*}{ Differentiation, n (\%) } & Differentiated & $75(48.1 \%)$ & $145(54.1 \%)$ & 0.231 \\
\hline & Undifferentiated & $81(51.9 \%)$ & $123(45.9 \%)$ & \\
\hline \multirow[t]{2}{*}{ Vascular invasion, n (\%) } & Negative & $154(98.7 \%)$ & $264(98.5 \%)$ & $>0.99$ \\
\hline & Positive & $2(1.3 \%)$ & $4(1.5 \%)$ & \\
\hline \multirow[t]{2}{*}{ Lymphatic invasion, $\mathrm{n}(\%)$} & Negative & $136(87.2 \%)$ & $221(82.5 \%)$ & 0.216 \\
\hline & Positive & $20(12.8 \%)$ & $47(17.5 \%)$ & \\
\hline \multirow[t]{2}{*}{ Perineural invasion, $\mathrm{n}(\%)$} & Negative & $148(94.9 \%)$ & $248(92.5 \%)$ & 0.421 \\
\hline & Positive & $8(5.1 \%)$ & $20(7.5 \%)$ & \\
\hline \multirow[t]{3}{*}{ Tumor Infiltration, n (\%) } & Expansile & $42(27.1 \%)$ & $59(22.0 \%)$ & 0.405 \\
\hline & Intermediate & $52(33.5 \%)$ & $104(38.8 \%)$ & \\
\hline & Infiltrative & $61(39.4 \%)$ & $105(39.2 \%)$ & \\
\hline \multirow[t]{3}{*}{ Lauren type, n (\%) } & Intestinal & $81(51.9 \%)$ & $135(50.4 \%)$ & 0.976 \\
\hline & Diffuse & $47(30.1 \%)$ & $84(31.3 \%)$ & \\
\hline & Mixed & $28(17.9 \%)$ & $48(17.9 \%)$ & \\
\hline Hospital stay, days & Mean \pm SD & $8.7 \pm 3.6$ & $9.3 \pm 5.0$ & 0.221 \\
\hline \multirow[t]{2}{*}{ Complication, n (\%) } & No & $120(76.9 \%)$ & $202(75.4 \%)$ & 0.726 \\
\hline & Yes & $36(23.1 \%)$ & $66(24.6 \%)$ & \\
\hline
\end{tabular}

AGC: Advanced gastric cancer; EGC: early gastric cancer; LNs: lymph nodes. *Seventh edition (9). 
often evaluated by immunohistochemistry during preoperative workup in South Korea, might therefore be useful prognostic markers for estimating patient survival.

It is important to note that there are a few limitations to this study. As the COX2-positive group showed a higher stage migration compared to the negative group, additional factors which alter preoperative staging should also be evaluated in detail, especially because tumor- and patientrelated factors can affect clinical staging. Furthermore, the question of whether co-expression of other markers related to the COX2 signaling pathway can affect mortality should also be answered in future studies.

Unfortunately, the specific HER2 status of patients was not included in this study. Data from the Trastuzumab for Gastric Cancer (ToGA) trial has shown that trastuzumab combination therapy improves mortality rates for advanced HER2-positive gastric cancer (20). In the ToGA trial, HER2 scoring was determined by immunohistochemical protein expression and fluorescence in situ hybridization (FISH), which is widely accepted as a standard method of HER2 diagnosis. FISH is limited for cases with equivocal (IHC2+) HER 2 expression. At the time of this study, most equivocal (IHC2+) cases had not undergone FISH testing because of cost barriers.

As this was a retrospective cohort study at a single center, only a small number of patients were enrolled. Additional multicenter-based trials with similar settings are required to achieve better results. Newly identified biomarkers, including E-cadherin, mutL homolog 1 and $\mathrm{CpG}$ island methylator phenotype, are currently under consideration as possible novel prognostic factors. At the time of this study, the aforementioned biomarkers were not evaluated at our center. Therefore, additional analyses of these new biomarkers should be performed in future studies.

\section{Conclusion}

This study illustrates the potential of COX2 as a novel biomarker for gastric cancer prognosis. Preoperative evaluation of COX2 might be a useful tool for developing optimal treatment strategies for gastric cancer, specifically for patients with clinical stage I.

\section{Conflicts of Interest}

All Authors have no conflicts of interest to disclose.

\section{Authors' Contributions}

This study was designed and directed by Dong Jin Kim and Wook Kim. Data were collected and analyzed by Dong Jin Kim. Tae Jung Kim performed and analyzed the immunohistochemistry results on specific biomarkers. The article was written by Dong Jin Kim and Hyun Joo Yoo and commented on by all Authors.

\section{References}

1 Global Burden of Disease Cancer Collaboration, Fitzmaurice C, Allen C, Barber RM, Barregard L, Bhutta ZA, Brenner H, Dicker DJ, Chimed-Orchir O, Dandona R, Dandona L, Fleming T, Forouzanfar MH, Hancock J, Hay RJ, Hunter-Merrill R, Huynh C, Hosgood HD, Johnson CO, Jonas JB, Khubchandani J, Kumar GA, Kutz M, Lan Q, Larson HJ, Liang X, Lim SS, Lopez AD, MacIntyre MF, Marczak L, Marquez N, Mokdad AH, Pinho C, Pourmalek F, Salomon JA, Sanabria JR, Sandar L, Sartorius B, Schwartz SM, Shackelford KA, Shibuya K, Stanaway J, Steiner C, Sun J, Takahashi K, Vollset SE, Vos T, Wagner JA, Wang H, Westerman R, Zeeb H, Zoeckler L, AbdAllah F, Ahmed MB, Alabed S, Alam NK, Aldhahri SF, Alem G, Alemayohu MA, Ali R, Al-Raddadi R, Amare A, Amoako Y, Artaman A, Asayesh H, Atnafu N, Awasthi A, Saleem HB, Barac A, Bedi N, Bensenor I, Berhane A, Bernabe E, Betsu B, Binagwaho A, Boneya D, Campos-Nonato I, Castaneda-Orjuela C, Catala-Lopez F, Chiang P, Chibueze C, Chitheer A, Choi JY, Cowie B, Damtew S, das Neves J, Dey S, Dharmaratne S, Dhillon P, Ding E, Driscoll T, Ekwueme D, Endries AY, Farvid M, Farzadfar F, Fernandes J, Fischer F, TT GH, Gebru A, Gopalani S, Hailu A, Horino M, Horita N, Husseini A, Huybrechts I, Inoue M, Islami F, Jakovljevic M, James S, Javanbakht M, Jee SH, Kasaeian A, Kedir MS, Khader YS, Khang YH, Kim D, Leigh J, Linn S, Lunevicius R, El Razek HMA, Malekzadeh R, Malta DC, Marcenes W, Markos D, Melaku YA, Meles KG, Mendoza W, Mengiste DT, Meretoja TJ, Miller TR, Mohammad KA, Mohammadi A, Mohammed S, Moradi-Lakeh M, Nagel G, Nand D, Le Nguyen Q, Nolte S, Ogbo FA, Oladimeji KE, Oren E, Pa M, Park EK, Pereira DM, Plass D, Qorbani M, Radfar A, Rafay A, Rahman M, Rana SM, Soreide K, Satpathy M, Sawhney M, Sepanlou SG, Shaikh MA, She J, Shiue I, Shore HR, Shrime MG, So S, Soneji S, Stathopoulou V, Stroumpoulis K, Sufiyan MB, Sykes BL, Tabares-Seisdedos R, Tadese F, Tedla BA, Tessema GA, Thakur JS, Tran BX, Ukwaja KN, Uzochukwu BSC, Vlassov VV, Weiderpass E, Wubshet Terefe M, Yebyo HG, Yimam HH, Yonemoto N, Younis MZ, Yu C, Zaidi Z, Zaki MES, Zenebe ZM, Murray CJL and Naghavi M: Global, regional, and national cancer incidence, mortality, years of life lost, years lived with disability, and disability-adjusted life-years for 32 cancer groups, 1990 to 2015: A systematic analysis for the Global Burden of Disease Study. JAMA Oncol 3(4): 524-548, 2017. PMID: 27918777. DOI: $10.1001 /$ jamaoncol.2016.5688

2 Mohri Y, Tanaka K, Ohi M, Yokoe T, Miki C and Kusunoki M: Prognostic significance of host- and tumor-related factors in patients with gastric cancer. World J Surg 34(2): 285-290, 2010. PMID: 19997918. DOI: 10.1007/s00268-009-0302-1

3 Sanz-Ortega J, Steinberg SM, Moro E, Saez M, Lopez JA, Sierra E, Sanz-Esponera J and Merino MJ: Comparative study of tumor angiogenesis and immunohistochemistry for p53, c-ERBB2, cMYC and EGFR as prognostic factors in gastric cancer. Histol Histopathol 15(2): 455-462, 2000. PMID: 10809364. DOI: 10.14670/HH-15.455

4 Mrena J, Wiksten JP, Kokkola A, Nordling S, Ristimaki A and Haglund C: COX2 is associated with proliferation and apoptosis markers and serves as an independent prognostic factor in gastric cancer. Tumour Biol 31(1): 1-7, 2010. PMID: 20237896. DOI: 10.1007/s13277-009-0001-4 
5 Martin HM, Filipe MI, Morris RW, Lane DP and Silvestre F: p53 expression and prognosis in gastric carcinoma. Int $\mathrm{J}$ Cancer 50(6): 859-862, 1992. PMID: 1555884. DOI: 10.1002/ijc. 2910500604

6 Li N, Deng W, Ma J, Wei B, Guo K, Shen W, Zhang Y and Luo S: Prognostic evaluation of NANOG, OCT4, SOX2, PCNA, Ki67 and E-cadherin expression in gastric cancer. Med Oncol 32(1): 433, 2015. PMID: 25491144. DOI: 10.1007/s12032-0140433-6

7 Schildberg C, Abbas M, Merkel S, Agaimy A, Dimmler A, Schlabrakowski A, Croner R, Leupolt J, Hohenberger W and Allgayer H: COX-2, TFF1, and SRC define better prognosis in young patients with gastric cancer. J Surg Oncol 108(6): 409413, 2013. PMID: 24037722. DOI: $10.1002 /$ jso.23416

8 Song J, Su H, Zhou YY and Guo LL: Cyclooxygenase-2 expression is associated with poor overall survival of patients with gastric cancer: a meta-analysis. Dig Dis Sci 59(2): 436-445, 2014. PMID: 24178897. DOI: 10.1007/s10620-013-2917-1

9 Washington K: 7th edition of the AJCC cancer staging manual: Stomach. Ann Surg Oncol 17(12): 3077-3079, 2010. PMID: 20882416. DOI: 10.1245/s10434-010-1362-z

10 Yasui W, Oue N, Aung PP, Matsumura S, Shutoh M and Nakayama H: Molecular-pathological prognostic factors of gastric cancer: A review. Gastric Cancer 8(2): 86-94, 2005. PMID: 15864715 . DOI: 10.1007/s10120-005-0320-0

11 Al-Moundhri MS, Nirmala V, Al-Hadabi I, Al-Mawaly K, Burney I, Al-Nabhani M, Thomas V, Ganguly SS and Grant C: The prognostic significance of p53, p27 KIP1, p21 WAF1, HER2/neu, and Ki67 proteins expression in gastric cancer: A clinicopathological and immunohistochemical study of $121 \mathrm{Arab}$ patients. J Surg Oncol 91(4): 243-252, 2005. PMID: 16121348. DOI: $10.1002 /$ jso. 20324

12 Zhang QW, Liu L, Chen R, Wei YQ, Li P, Shi HS and Zhao YW: Matrix Metalloproteinase-9 as a prognostic factor in gastric cancer: A meta-analysis. Asian Pacific J Cancer Prev 13(6): 2903-2908, 2012. PMID: 22938481. DOI: 10.7314/apjcp. 2012.13.6.2903

13 Alsina M, Landolfi S, Aura C, Caci K, Jimenez J, Prudkin L, Castro S, Moreno D, Navalpotro B, Tabernero J and Scaltriti M: Cyclin E amplification/overexpression is associated with poor prognosis in gastric cancer. Ann Oncol 26(2): 438-439, 2015. PMID: 25403579. DOI: 10.1093/annonc/mdu535
14 Chen C, Yang JM, Hu TT, Xu TJ, Yan G, Hu SL, Wei W and Xu WP: Prognostic role of human epidermal growth factor receptor in gastric cancer: a systematic review and meta-analysis. Arch Med Res 44(5): 380-389, 2013. PMID: 23871709. DOI: 10.1016/j.arcmed.2013.07.001

15 Oshima H, Oshima M, Inaba K and Taketo MM: Hyperplastic gastric tumors induced by activated macrophages in COX2/mPGES-1 transgenic mice. EMBO J 23(7): 1669-1678, 2004. PMID: 15014433. DOI: 10.1038/sj.emboj.7600170

16 Rajnakova A, Moochhala S, Goh PM and Ngoi S: Expression of nitric oxide synthase, cyclooxygenase, and p53 in different stages of human gastric cancer. Cancer Lett 172(2): 177-185, 2001. PMID: 11566494. DOI: 10.1016/s0304-3835(01)00645-0

17 van Rees BP, Saukkonen K, Ristimaki A, Polkowski W, Tytgat GN, Drillenburg $P$ and Offerhaus GJ: Cyclooxygenase-2 expression during carcinogenesis in the human stomach. J Pathol 196(2): 171-179, 2002. PMID: 11793368. DOI: 10.1002/ path.1033

$18 \mathrm{Li} \mathrm{Y,} \mathrm{Tan} \mathrm{BB,} \mathrm{Fan} \mathrm{LQ,} \mathrm{Zhao} \mathrm{Q,} \mathrm{Liu} \mathrm{Y} \mathrm{and} \mathrm{Wang} \mathrm{D:} \mathrm{Expression}$ of COX-2, survivin in regional lymph node metastases of gastric carcinoma and the correlation with prognosis. Hepatogastroenterology 57(104): 1435-1441, 2010. PMID: 21443099.

19 Hottenrott C and Katsios C: Prognostic significance of host- and tumor-related factors in patients with gastric cancer. World $\mathrm{J}$ Surg 34(10): 2496-2497; author reply 2498, 2010. PMID: 20376446. DOI: 10.1007/s00268-010-0554-9

20 Bang YJ, Van Cutsem E, Feyereislova A, Chung HC, Shen L, Sawaki A, Lordick F, Ohtsu A, Omuro Y, Satoh T, Aprile G, Kulikov E, Hill J, Lehle M, Ruschoff J, Kang YK and To GATI: Trastuzumab in combination with chemotherapy versus chemotherapy alone for treatment of HER2-positive advanced gastric or gastro-oesophageal junction cancer (ToGA): A phase 3, open-label, randomised controlled trial. Lancet 376(9742): 687-697, 2010. PMID: 20728210. DOI: 10.1016/S01406736(10)61121-X
Received November 19, 2019

Revised November 28, 2019

Accepted November 29, 2019 